\title{
HISTÓRIA EMPRESARIAL NO BRASIL: UM BALANÇO HISTORIOGRÁFICO ATÉ AO INÍCIO DOS ANOS 90*
}

\author{
Almir Pita Freitas Filho**
}

\section{INTRODUÇÃO}

Um ramo da História Económica, a História Empresarial, tem tido a sua difusão bastante limitada nos meios académicos brasileiros. Assim, até meados dos anos 60, não se havia instituído entre nós uma tradição de estudos e de pesquisas que tivessem como tema o empresário e/ou a empresa. Praticamente um único empresário, lrineu Evangelista de Souza, o Visconde de Mauá, tinha sido alvo de um exame mais detalhado por parte de historiadores.

Além de Mauá, tem-se notícias de trabalhos sobre empresas ferroviárias, do sector bancário e de casas comerciais, assim como de empresas agrícolas (engenhos de cana-de-açúcar, por exemplo) e de mineração. O quadro, porém, não era animador, uma vez que muitos destes estudos eram tributários de uma visão tradicional do "fazer história", onde predominava a descrição, uma abordagem quase sempre apologética da figura do empresário ou da empresa, cuja explicação para o crescimento, sucesso e/ou fracasso do empreendimento se iniciava e esgotava nele próprio.

Embora alterações neste quadro possam ser assinaladas a partir de meados dos anos 60, com a publicação do trabalho pioneiro de José de Souza Martins sobre o Conde Matarazzo e o artigo de Richard Graham sobre a Rio de Janeiro Flour Mills and Granaries, a crise que atingiu a História Económica na década de 70, nos principais centros académicos, também se repercutiu no Brasil e resultou numa diminuição do interesse pelos estudos retrospectivos de economia em geral.

Mesmo, nos anos 80 , sendo já possível detectar a existência de abordagens mais originais, influenciadas teórica e metodologicamente por historiadores e economistas europeus e norte americanos, a exemplo de J. A. Schumpeter,

** Faculdade de Economia e Administração - Universidade Federal do Rio de Janeiro (UFRJ). 
A. Cole, Charles Wilson, Jean Bouvier, Barry Suply, Alfred Chandler, entre outros, a História Empresarial ainda aparece no Brasil como um campo que desperta pouco interesse, tanto para pesquisadores quanto para empresários e empresas.

Neste artigo são levantadas algumas hipóteses explicativas para este atraso no estabelecimento e no país, de uma tradição de estudos sobre o tema empresarial, além de apresentar um balanço, dos principais trabalhos publicados nos anos 80 sobre o assunto. Por fim, partindo de novas abordagens sobre a "Business History", sugerir-se-ão possibilidades de estudos no Brasil.

\section{DIFICULDADES NO ESTUDO DA HISTORIA EMPRESARIAL}

As dificuldades encontradas para realização e difusão de estudos sobre História Empresarial parecem não ser exclusivas dos meios académicos brasileiros. Daviet (1990) assinalava que a "lenta maturação" da "Business History" só se completa por volta da década de 70, tanto na Europa quanto nos Estados Unidos. Dentre os indicadores desta viragem eram destacados: a publicação do livro de A. Chandler Jr., "The Visible hand", em 1977; a instalação da "Business History Unit" na London School of Economics; a criação de associações e sociedades voltadas para o estudo e pesquisa sobre empresas, a exemplo da Fundação ASSI (Daviet, 1990: 21-28). Este novo quadro atestaria a imaturidade da História Empresarial e a consolidação de uma área profícua de estudos e pesquisa, enquanto subsistissem problemas de ordem temática, metodológica e documental.

$\mathrm{O}$ amadurecimento da História Empresarial no exterior era ainda marcado por questões de ordem institucional. Hannah (1983: 167) chamava atenção para o isolamento que caracterizou o desenvolvimento deste campo de estudo na Grã-Bretanha:

Business History has grown naturally within the structure of British universities in which economic history departments are typically quite separete both from mainstream history and from economies and the other sciences.

Ao desinteresse dos departamentos pela "Business History", somava-se o distanciamento entre o ambiente empresarial e o universitário, assim como a qualidade dos trabalhos sobre o tema que, com raras excepções, permaneciarn apegados a uma tradição descritiva e isolacionista, onde a problematização e o suporte conceitual raramente estavam presentes. Tratava-se de um dos pontos fracos, também assinalados por Hannah (1983: 166):

Most business historians have clung to a tradition which, at the best, is a triumph of narrative skill, honest to the facts of the individual case, but at the worst is narrow, insular and antiquarian". 
Percebe-se, portanto, a existência de uma problemática comum relacionada com a difusão dos estudos empresariais, à qual devem ser acrescidas as peculiaridades da evolução da História Económica, o que será tratado em seguida, tendo como referencial a situação do Brasil.

\section{3. "ESTADO DA ARTE" DA HISTÓRIA ECONÓMICA}

A reflexão crítica em torno dos problemas estruturais do Brasil e da sua história tem sido, em diversos momentos, influenciada por modismos temáticos e metodológicos. Não é de se estranhar, portanto, que na actualidade a História Económica se encontre em baixa cotação nos meios académicos e de pesquisa.

A partir dos anos 70 a abordagem económica, que ainda exercia uma forte influência nos cursos de História das principais universidades dos grandes centros culturais do país, tornava-se cada vez menos atraente aos aspirantes ao ofício de historiador. A nível dos estudos históricos era fácil constatar o início da hegemonia dos temas ligados à chamada "Nouvelle Histoire", tais como as mentalidades, as práticas quotidianas, a sexualidade, eclipsando o interesse dos estudantes universitários e do público leitor em relação aos assuntos puramente económicos`.

Embora sejam diversas as causas desta situação, um aspecto deve ser ressaltado: a forte influência da historiografia francesa nos meios académicos do país, em especial do grupo dos "Annales".

Ao tornar hegemónica a sua problemática, os seus métodos e objectivos de estudo, os ANNALES, especialmente em suas duas fases, deram frutos bastante positivos, difundido e consolidando nos centros de pesquisa histórica uma directriz de combate à história tradicional. Entretanto, a forte influência de L. Febvre, Marc Bloch, F. Braudel e seus discípulos limitou a divulgação, entre nós, de uma outra tradição de trabalhos, realizados por historiadores económicos, particularmente nos Estados Unidos e na Grã-Bretanha.

Apesar da crise que atingiu a História Económica em quase todos os países a partir de meados dos anos 70 (Cipolla, 1991: 74), pesquisas continuaram a ser realizadas e divulgadas em encontros anuais ou nas páginas de periódicos especializados, tais como: "Economic History Review", "Journal of Economic History", "Business History Review", "Explorations in Economic History", "Journal of Economic And Business History", "Revista de História Económica". Nestas publicações, ao contrário dos ANNALES pós-Braudel, os temas característicos da história económica não estavam ausentes, conquanto a sua circulação e o número de seus leitores fosse, com certeza, cada vez mais reduzido no Brasil.

Por sua vez, a chamada "New Economic History", nos anos 60, teve, entre nós, maior repercussão entre os economistas com alguma formação histórica, que desenvolveram trabalhos de pesquisa a partir das propostas metodológicas 
daquela corrente. A resistência dos historiadores em estreitarem o contacto com disciplinas teóricas, como a Economia, certamente dificultou-nos a realização dos "encontros" de que nos fala Bouvier (1976: 135).

Os factores acima arrolados condicionaram os rumos da pesquisa e do ensino da História Económica no Brasil, nas duas últimas décadas. A geração de historiadores recém-formada, que conseguiu ingressar na vida universitária ou nos centros de pesquisa, foi levada, por um modismo ou pressão do meio académico, a abraçar temas mais do agrado, tanto dos meios de comunicação e das linhas de publicação das editoras, quanto das agências financiadoras e de um número cada vez mais reduzido de candidatos aos cursos de História. Proliferava a geração da "História ao microscópio" (Cardoso, 1988: 106), para a qual a discussão sobre o "sentido da colonização" era substituída pela da sexualidade ou da bruxaria no período colonial.

Esta trajectória, no entanto, não foi comum a todos aqueles que tiveram uma formação em História Económica. Aos historiadores que permaneceram ligados a seus departamentos, embora oferecendo "créditos extensos", ou os que foram absorvidos pelos de Economia, restou-lhes o isolamento e as sobras dos parcos recursos, materiais e humanos, que ambos ainda eram capazes de disputar (uma situação muito semelhante à descrita por Wallerstein ${ }^{2}$ ). Entretanto, este novo quadro, ao possibilitar um maior contacto com economistas profissionais, redundou, para o historiador, num arejamento teórico, metodológico e também temático.

As questões de ordem macroeconómica, de economia internacional, economia do trabalho, de administração e dinâmica das empresas; o uso de métodos estatísticos e econométricos para a variação da renda, dos preços e dos salários; as estratégias de crescimento das grandes empresas; o papel das inovações tecnológicas e, por fim, o retorno das crises económicas, indicando o esgotamento do crescimento e da prosperidade dos anos do pós-Segunda Guerra, eram temas do interesse dos economistas, mas que passaram também a sensibilizar os historiadores económicos, contrarrestando a sedução da "Nouvelle Histoire".

A tendência para a fragmentação que dominava a pesquisa histórica também influenciou a História Económica, fazendo-a recuar da pretensão de construir grandes sínteses explicativas, voltando-se para temas espacial e temporalmente mais limitados. Além do mais, levou a disciplina a uma maior abertura no que se refere ao uso de novas fontes e métodos emprestados por outras áreas do conhecimento.

Beneficiando deste duplo movimento, de aversão às grandes sínteses e de envolvimento com problemáticas típicas dos estudos económicos, a abordagem empresarial e os estudos sobre empresas ofereceram ao historiador económico um campo fecundo de pesquisa, um espaço para renovação da História Económica no Brasil. Isto porque, ao estudar as unidades de produção e seus agentes, buscando desvendar os mecanismos internos de funcionamento, as técnicas de produção, de 
administração, de controle da força de trabalho, suas relações com o entorno social, político, cultural e natural, no qual a empresa se insere e evolui, assim como as formas de pensamento e acção de proprietários e administradores, a História Empresarial revela, a nível microscópio, os homens em acção, fazendo sua história, inclusive quotidiana. E, sob a perspectiva de uma história total, os estudos empresariais conduzem à renovação do conhecimento sobre a formação da classe empresarial, suas origens e ideologia, de suas forças materiais, seu papel político e social, dos diferentes sectores da vida económica - industrial, agrícola, comercial, financeira - assim como de seus principais ramos.

Ulf Olsson (1990: 63), ao sintetizar o desenvolvimento da "Business History" na Suécia, também chamava a atenção para as possibilidades oferecidas pelos estudos sobre empresas:

Many of the fundamental processes in society can be studied and better understood by looking at the firm; the changing role of the state, technological development, growing regional disparities, and so on. Business History is needed - directlv or indirectly - to build and test theories of how the economy evolves.

\section{A HISTÓRIA EMPRESARIAL NO BRASIL}

\subsection{Indústria}

No Brasil, a História Empresarial é ainda um campo de estudo a ser desenvolvido. Poucos têm sido os empresários e empresas que, interessados em resgatar o seu passado, confiaram esta tarefa a historiadores profissionais. Até ao início dos anos 70 ainda não se havia instituído, nos principais centros de pesquisa do país, uma tradição de estudos neste campo. Contribuía, para tanto, além dos factores anteriormente mencionados, uma arraigada tradição de se considerar os poderes públicos, o Estado, como o agente preponderante no processo de modernização capitalista do país, especialmente a partir da década de 30. Esta visão, que tinha como corolário a atribuição de uma actuação subordinada e/ou passiva aos demais grupos sociais, tanto trabalhadores quanto empresários, conquanto esteja sendo actualmente revista, retardou o desenvolvimento de pesquisas que tivessem como objecto o empresário e a empresa.

Embora raros, não eram totalmente inexistentes estudos voltados para o tema empresarial. Irineu Evangelista de Souza, o visconde de Mauá, tido como pioneiro da industrialização do país, é, com certeza, até aos dias actuais, o empresário alvo de exame mais detalhado pela historiografia nacional. A excepcionalidade de sua trajectória, durante o período imperial, ocasião em que a actividade mais lucrativa assentava na compra e venda de escravos, aliada à publicação de documentos que registam as suas vicissitudes enquanto empresário num meio social aparentemente adverso a tais experimentos, tem atraído o interesse de diversos historiado- 
res. Entretanto a ampla literatura sobre Mauá possui uma característica mais biográfica, muitas vezes polémica, como quando tenta esclarecer a sua ligação com o governo imperial e o capital britânico, mas que se esgota no próprio objecto. O trecho a seguir ilustra esta concepção (Besouchet, 1978: 16):

A figura de Mauá, (...) é de uma singularidade impressionante: seu ideal (...) é o mais claro e concreto que surge no país no século XIX. Depois de Feijó, cremos que ninguém viu com tanta clareza a enorme potencialidade do Brasil como país, como nacionalidade.

Enquanto a trajectória de Mauá suscitou, e tem continuado a suscitar, estudos e publicações variadas, o mesmo não ocorreu, por exemplo, com Delmiro Gouveia, um dos pioneiros na produção de energia eléctrica para fins industriais e ainda uma das mais famosas "vítimas" da penetração do capital estrangeiro no Brasil, no início do século XX. $\mathrm{O}$ episódio da compra da sua fábrica de linhas pela firma inglesa Machine Cotton e a sua posterior demolição é, frequentemente, apresentado como exemplo da intransigência do capital alienígena diante das tentativas de desenvolvimento do sector industrial no país (Fausto, 1985: 174).

Além de trabalhos sobre Mauá, têm sido publicadas histórias de empresas industriais, de ferrovias, bancos e casas comerciais, algumas das quais por iniciativa de administradores ou ex-dirigentes. Na maioria das vezes trata-se de verdadeiras histórias dos acontecimentos, onde predomina uma abordagem descritiva, factual, não ultrapassando uma ordenação cronológica de eventos, decretos, episódios mercantes, que buscam dar um testemunho da "vida" dessas firmas ou de seus proprietários. $O$ interesse do pesquisador sobre esta literatura circunscreve-se às fontes documentais apresentadas, compensando a falta de um aparato teórico, já que as explicações para os sucessos e/ou fracassos, quando presentes, se iniciam e esgotam no interior do próprio objecto.

Um exemplo recente deste tipo de abordagem é o ensaio biográfico sobre Guilherme Guinle, publicado em 1982, por ocasião da comemoração do centenário de nascimento deste empresário (Barros, 1982). O autor realiza uma reconstituição da vida do biografado, centrada nas suas actividades, nos seus diversos empreendimentos, na sua trajectória enquanto homem público, assim como na sua acção cultural e beneficente. Porém, conquanto os direitos da edição sejam da C. ${ }^{\text {ia }}$ Docas de Santos, uma das empresas do empresário, as principais fontes utilizadas não são os relatórios e actas da companhia, mas sim depoimentos e artigos de jornais.

É possível, no entanto, registar a existência de abordagens mais originais, tanto do ponto de vista temático, quanto teórico e metodológico.

Foi sem dúvida o trabalho pioneiro de José de Souza Martins (Martins, 1976), sobre o Conde Matarazzo, publicado em 1967, que inaugurou uma forma original, ou seja, não apologética e atomizada, de se estudar o empresariado nacional, na génese da indústria brasileira. Partindo de um quadro teórico inspirado nos clássicos J. A. Schumpeter e W. Sombard, utilizando informações obtidas em memó- 
rias, relatos e biografias de Francisco Matarazzo, o autor analisa o tipo de empresa e o comportamento do empresário que seriam característicos do período de emergência de uma economia industrial, no contexto de dissolução das relações mercantis. Segundo Martins, aquelas condições teriam facilitado a produção de paradoxos com Matarazzo, onde uma racionalidade técnica, tipicamente capitalista, convivia como uma outra, mercantil, tradicional, que caracterizava a acção do empresário, influenciando tanto na condução dos negócios, quanto no trato para com os trabalhadores. Para Martins (1976: 106), o "paradoxo" explicitar-se-ia no facto de que:

A empresa não realiza todas as suas virtualidades técnicas na fase de institucionalização da indústria brasileira, mas fica submetida à sensibilidade empírica do comerciante-industrial que decide, que confronta a indústria com o mercado, que leva para o interior da primeira as suas possibilidades.

Na mesma ocasião o historiador norte americano Richard Graham publicou um artigo sobre a história da "Rio de Janeiro Flour Mills and Granaries", uma empresa britânica instalada em 1886, para produção de farinha de trigo (Graham, 1966: 13), que também pode ser considerado um referencial na abordagem sobre o tema. Partindo da documentação da própria empresa, que era administrada à distância, o autor examinou como foram sendo superados os obstáculos iniciais enfrentados pela companhia, em sua maioria decorrentes de sua localização num meio social "tropical e subdesenvolvido". Insuficiente capital de reserva, dificuldades na reposição de peças portuárias, epidemias, instabilidade política e cambial, hábitos alimentares, se somavam aos problemas de ordem administrativa. Graham considera que (Graham, 1966: 15):

One of the most important causes of the company's plight was the inherent difficulty os running company whose plant was so far from its directors. Although cable communications were possible, ordinary correspondence took several weeks. More important was the fact that it was practically impossible to become intimately familiar with local conditions at this distance.

Porém, na medida em que tais problemas foram sendo solucionados, a empresa desenvolveu-se, distribuindo os primeiros dividendos em 1893, e não deixando mais de fazê-lo até 1920 . O autor concluiu que o crescimento verificado no período e o sucesso foram possíveis na medida em que se adoptaram estratégias empresariais adequadas às condições locais (Graham, 1966: 37).

Os dois trabalhos citados são exemplos de abordagens que tratam, tanto da empresa quanto do empresário, de forma não isolada, privilegiando a relação de ambos com o meio social, do qual participam, e com os problemas decorrentes desta situação. Conquanto ambos sejam analisados a partir de uma perspectiva intensa, observa-se uma forte influência dos factores extensos na explicação para 
o comportamento do Conde Matarazzo e do quadro dirigente-administrativo da empresa britânica.

Exemplos recentes de enfoques mais próximos de concepções modernas da historiografia económica podem ser encontrados em alguns trabalhos já publicados, assim como em várias teses e dissertações, ainda inéditas, atestando não só a vitalidade do enfoque empresarial como também as suas possibilidades na produção histórica do país. Entre os primeiros, destaca-se o estudo de Elizabeth von der Weid e Ana Marta Bastos sobre a América Fabril (Weid e Bastos, 1986), uma empresa têxtil bastante representativa do sector, localizada no Rio de Janeiro, no período de 1876 a 1930.

Tendo tido acesso a uma documentação rica e preservada, as autoras procuram analisar, através de um estudo de caso, o processo de formação e de expansão do sector têxtil no Brasil. Para tanto se concentram nas fases de implantação e de expansão da América Fabril, destacando em cada uma delas o tipo de empresa, a estrutura administrativa, o perfil dos dirigentes e a mentalidade empresarial que os orientava na adopção de estratégias e políticas relativas à produção, finanças e força de trabalho.

Um estudo bastante original sobre a formação do operariado industrial no país nas décadas finais do século XIX é feito por Domingos Giroletti, em Fábrica. Convento. Disciplina (Girolletti, 1991). $O$ autor examina de forma detalhada as principais estratégias adoptadas pelos empresários de um importante grupo têxtil, situado em Minas Gerais, a C. ${ }^{\text {ia }}$ Cedro e Cachoeira, na criação de um trabalhador adaptado técnica, disciplinar e ideologicamente à nova realidade fabril. O estudo, uma contrapartida nacional do trabalho de Graham, privilegia um dos ângulos da acção empresarial, aquele relativo às relações de trabalho, aos problemas enfrentados pelo empresariado nacional na criação de uma mão-de-obra ajustada ao universo capitalista, num meio social ainda bastante impregnado não só pelas práticas, mas também pela mentalidade agro-patriarcal. Tratase de um tema que pode ser considerado como parte importante na construção da uma Cultura da Empresa.

Allison M. Vaz, por sua vez, discorre sobre a história do mesmo grupo empresarial mineiro, a C. ${ }^{\text {ia }}$ de Fiação e Tecidos Cedro e Cachoeira, desde a sua origem, em 1883, até 1987 (Vaz, 1990), apresentando uma contribuição para o estudo da gestão familiar de empresas no Brasil, já que, durante mais de um século, o grupo Mascarenhas manteve o controle dos negócios. Neste sentido, o autor procura destacar os mecanismos económicos, financeiros e sociais empregados pela administração que, desde o final do século passado até os anos $\mathbf{8 0}$ do actual, foram responsáveis pelos sucessos e fracassos vivenciados pela empresa, assim como as razões que levaram à manutenção do controle familiar sobre o grupo. Trata-se de um trabalho de grande interesse histórico, na medida em que, ao procurar esclarecer a longa duração de uma administração familiar, indica possíveis hipóteses 
explicativas para o facto de, até os dias actuais, grande parte das empresas brasileiras, muitas de grande porte, ainda permanecerem sob o controle financeiro e administrativo de membros da família fundadora.

Nos dois exemplos assinalados, os autores contaram com uma situação excepcional no tocante à existência e ao acesso à documentação da empresa. Num dos raros exemplos de que se tem notícia no país, o grupo Mascarenhas dispõe de um arquivo e um museu particular, onde a documentação se encontra preservada e acessível ao pesquisador interessado.

Além da rica documentação apresentada, os trabalhos citados destacam-se por deslocarem o enfoque tradicional sobre a indústria brasileira do eixo Rio - São Paulo, estudando aspectos da história de empresa e empresários de Minas Gerais, uma unidade da federação até então fora do "mainstream" teórico sobre o processo de industrialização do Brasil.

Uma amostra das possibilidades da abordagem empresarial de renovar interpretações aparentemente consolidadas, reunindo argumentos capazes de ajudar no esclarecimento de questões controversas da historiografia tradicional da economia, é apresentada no estudo de Douglas Libby sobre a Mina de Morro Velho, um investimento britânico de alta rentabilidade, no século XIX, em Minas Gerais (Libby, 1984). Apoiando-se principalmente na documentação oriunda dos arquivos da própria companhia, Libby examinou de que forma a St. John d'EI Rey, entre 1835 e 1885 , empregou o trabalho escravo juntamente com métodos "modernos" de administração e tecnologia, atenuando as versões que apontavam para a irracionalidade económica do sistema escravista e sua incapacidade de adoptar práticas "racionais", identificadas como exclusivas do capitalismo. Ao analisar as operações da empresa mineradora, actuando num meio social escravista, predominantemente agrícola, Libby discute pontos controversos da historiografia sobre a escravidão, apontando para um importante canal de acumulação interna de capital, além da possibilidade de se conciliarem duas formas aparentemente incompatíveis de nacionalidade económica. Tendo desenvolvido suas operações num período de transição do trabalho escravo para o livre, a Morro Velho exemplificaria, segundo Libby, um "empreendimento transicional".

Quando se trata de examinar a actuação do empresário, destaca-se o trabalho de Palmira Petratti Teixeira sobre a trajectória de Jorge Street, um industrial portador de ideias modernizantes, presente na vida política e social do país nas décadas inicias deste século (Teixeira, 1990). A autora analisa o percurso deste porta-voz dos industriais que, no início do século XX, além de se notabilizar como defensor das ideias nacionalistas relativas à indústria, propunha aos seus pares a adopção de novas estratégias no trato para com os trabalhadores. Vivendo numa época onde a mentalidade dominante tratava a "questão social" através de métodos policiais, Street inovou ao defender a aceitação do direito à greve e à sindicalização, e a criação de uma legislação social. Aspectos do pensamento e da prática 
social de Jorge Street, tais como a sua actuação nas associações patronais durante a República Velha, o seu contributo para a criação de uma legislação trabalhista nas décadas de 20 e 30, a idealização e construção da Vila Operária Maria Zélia, são resgatados pela autora. $O$ trabalho de Palmira Teixeira traça uma fértil directriz de pesquisa no sentido de se desvendarem os campos de actuação do empresariado nacional fora da fábrica, da empresa. Outros empresários, a exemplo de Euvaldo Lodi, continuam à espera de um exame mais detalhado de sua trajectória, tanto pública quanto privada, conforme o que foi realizado no trabalho em questão.

Os exemplos apresentados até aqui reflectem a produção de historiadores profissionais, e são indicadores de urna abordagem inovadora, não atomizada, sobre o tema da empresa e/ou do empresário, até o início da década de 90. Resta, por último, apontar para a existência de um número expressivo de teses e dissertações, ainda inéditas, expressando a institucionalização da pesquisa universitária, realizadas tanto por economistas quanto por historiadores, dos principais centros académicos do país, sobre a história de empresas ou de empresários de, entre outros, Rio de Janeiro, São Paulo, Baía, Minas Gerais, Santa Catarina. Em artigo anterior (Freitas Filho, 1989: 168) relacionámos alguns destes trabalhos, aos quais acrescentamos a tese de doutoramento de Ana Célia Castro, sobre a empresa Agroceres (Castro, 1988).

Empresa pioneira no país na produção de sementes de milho híbrido, a Agroceres cresceu através da entrada num mercado já dominado pela presença de empresas multinacionais. Ana Castro relata a trajectória da empresa na diversificação da sua pauta de produtos e/ou de processos produtivos, como resposta às alterações nas condições do seu funcionamento e na evolução da economia em geral. Esta diversificação teria sido responsável por mudanças em sua estrutura organizacional, passando de um modelo de organização tradicional para um multidivisional - segundo o conceito chandleriano -, com características diferenciais no tocante às operações de gerência (Castro, 1988: 12). Obra de economista, mas com olhos voltados para a história, infere-se do trabalho uma preocupação em discutir a relação entre mudanças organizacionais e tecnológicas, tributária da concepção chandleriana de crescimento das empresas.

\subsection{Sector dos serviços}

Empresas do sector de serviços, tanto públicas quanto privadas, também vêm sendo estudadas e transformadas em objectos de teses ou pesquisas. Este movimento tem sido favorecido por vários factores, de entre eles o interesse das próprias empresas que, diante dos desafios contemporâneos, se preocupam em resgatar suas experiências passadas, até como forma de rever aspectos de sua cultura, passíveis de auxiliá-las no presente; ou ainda como resultado da implementação de programas de preservação e organização de sua documentação, tornando-a acessível a pesquisadores externos ou com algum vínculo à empresa. É o exemplo da pesquisa realizada pela equipa coordenada pelas professoras Maria Bárbara 
Levy e Eulália M. Lahmeyer Lobo sobre a História da Rio Light, uma empresa de capital estrangeiro que se instalou na cidade em 1905, dedicando-se, de entre outros, ao fornecimento de energia eléctrica, e que foi comprada pelo governo federal em 1979.

Trabalhando com uma documentação ainda em estágio preliminar de organização, a pesquisa focou a empresa sob quatro ângulos: o do seu papel enquanto empresa de capital estrangeiro no sector de serviços públicos do Rio de Janeiro, sua origem e transformações até ser comprada pelo governo federal em 1979; b) enquanto fornecedora de energia eléctrica e geradora de tecnologia, cujos investimentos foram decisivos para 0 aumento do potencial energético da região; c) a actuação de alguns de seus primeiros directores e accionistas - Alexandre Mackenzie, Percival Farquhar, Alfredo Maia - através de um estudo biográfico; d) e, por fim, uma reconstituição das formas de organização administrativa da empresa, ao longo do período, inspirada nos trabalhos de Alfred Chandler sobre as modernas empresas capitalistas. ${ }^{3}$

E, para finalizar este balanço historiográfico, cabe mencionar um dos principais problemas com que se depara a história empresarial, particularmente no Brasil: o acesso à documentação das empresas. Ter acesso a estas fontes, aos arquivos empresariais, juntamente com uma sólida formação teórica do investigador e o uso de uma metodologia adequada ao tratamento dos dados, são condições básicas, capazes de garantir ao enfoque empresarial um padrão de cientificidade e objectividade. São pressupostos mínimos, capazes de atenuar a realização de trabalhos de cunho panegírico, jornalístico, quase sempre enaltecedores da empresa e do empresário, vistos como portadores de uma racionalidade schumpeteriana, onde é muito comum a ausência de uma abordagem crítica. Os trabalhos citados neste balanço puderam ser realizados na medida em que contaram com condições excepcionais, no tocante ao acesso e uso da documentação. Porém, na maioria das vezes, a realidade do pesquisador interessado neste tipo de abordagem é bem adversa, chegando a constituir-se num dos principais obstáculos e a retardar, entre nós, o desenvolvimento desses estudos e, consequentemente, do próprio conhecimento da história económica e social do país.

Se, por um lado, ainda persiste entre a maioria do empresariado um certo desinteresse em conhecer a sua história e uma desconfiança em relação ao historiador, por outro, quando estes obstáculos são superados, o pesquisador depara-se com uma documentação incompleta, desorganizada e num precário estado de conservação, comprometendo, com isso, a realização de seu trabalho. É bem verdade que algumas empresas, dando-se conta da importância estratégica em resgatar o seu passado, têm procurado o organizar o respectivo património documental, contratando para esta tarefa profissionais especialistas, e até mesmo incentivando a formação de departamentos encarregados de cuidar e preservar a sua memória. 
No mercado dos maiores centros urbanos do país já existem algumas empresas de consultoria e pesquisa histórica, voltadas para atender a esta demanda ainda tímida.

Alguns dirigentes de empresas estão, é bem verdade, percebendo a importância do conhecimento da sua história, especialmente numa época de transformações amplas como as das duas últimas décadas. Estes tempos estariam indicando que, soluções inovadoras, estratégias de expansão ou simplesmente de sobrevivência, podem estar ligadas a experiências passadas, à recuperação de sua identidade, desconhecida tanto para o público quanto para as novas gerações de administradores ${ }^{4}$. Entretanto, exemplos como o da CEDRO E CACHOEIRA, que criou o Museu Industrial Décio Mascarenhas para preservação de sua história; do empresário José Midlin; do SENAI-SP, que criou recentemente um Núcleo de Memória, da ELETROPAULO, que possui um departamento de Património Histórico, continuam sendo raros.

\section{CONCLUSÃO}

Mesmo já sendo possível apresentar um conjunto de trabalhos originais sobre o tema, a história empresarial é ainda um campo de investigação a ser explorado no Brasil; resta-nos ainda muito a fazer.

E, partindo da produção existente, tendo em conta os problemas referentes à documentação, são esboçados a seguir algumas propostas de investigação que se configuram mais pertinentes neste contexto:

a) novos estudos que, tendo como referencial as linhas de pesquisa já existentes e utilizando particularmente o método comparativo, possam aprofundar questões ali presentes, a exemplo do papel do ambiente social na formação do empresário, ou ainda sobre o papel de empresários e empresas no desenvolvimento económico de diferentes regiões do país ou períodos;

b) um estreitamento do contacto entre historiadores e a produção dos centros de economia, capaz de resultar no enriquecimento do quadro teórico dos primeiros e num maior mergulho da economia no ambiente histórico. Tal intercâmbio poderia ser estruturado a partir da criação de linhas de pesquisa conjuntas que procurassem divulgar e desenvolver no país as ideias, por exemplo, de Alfred Chandler, estudando a pertinência das mesmas para analisar a dinâmica de empresas centradas numa economia industrializada tardiamente, onde o Estado e o capital internacional tiveram uma participação decisiva, ${ }^{5}$

c) um exame do papel da pequena e da média empresa no Brasil que, embora mantenham uma elevada participação na estrutura produtiva do país, têm sido pouco estudadas entre nós, no que concerne às suas formas de evolução, de propriedade e administração, de padrão tecnológico; suas relações com as grandes 
empresas, o sector financeiro, os poderes públicos e os mercados, de entre outros; trata-se de temas passíveis de serem comparados com os das grandes corporações, esclarecendo possíveis diferenças de gestão, já que a persistência de uma gestão familiar parece não ser uma prerrogativa das primeiras.

d) por fim, e nunca é demais lembrar, a elaboração de instrumentos de pesquisa, de material de referência como biografias, bancos de dados e de entrevistas com empresários, dirigentes de empresas, gerentes, técnicos, empregados, fornecedores e consumidores.

O fortalecimento dos estudos de história empresarial, partindo destas directrizes, sem dúvida fornecerá novas interpretações, novas visões, que permitirão uma melhor compreensão, uma melhor abordagem, sobre a história económica do Brasil, tanto passada quanto presente.

\section{NOTAS}

* Uma versão anterior deste texto foi apresentada no Congresso Brasileiro de História Económica e Segunda Conferência Internacional de História de Empresas, realizado em São Paulo, FEA/USP, 7 a 10 de Setembro de 1993.

' Para uma curta e contundente avaliação da Nova História ver: Cardoso, Ciro F. S., Ensaios racionalistas. Rio de Janeiro, Campus, 1988, p. 93-117; François, Dose, A História em migalhas. Dos Annales à Nova História. São Paulo, Ensaio; Campinas, Editora da Unicamp, 1992.

2 "Economic historians, it is well know, are sometimes located organizationally within departments of history. It is also well know that some (...) economics departments do not wish to house economic historians, and that some history departments fell the same way (...). All of this reflects the somewhat anomalous status of economic history within the university system we have today. It is a bit as though economic history were na unwanted stepchild, a Cinderella in rags." Cf.: I. Wallerstein. 1991, "A Theory of Economic Hstory in place of Econormic Theory", Revue Economique, vol. 42, n. 2 , mars, p. 173.

${ }^{3}$ Esta pesquisa foi concluída em fins de 1990. Um resumo dos resultados foi apresentado por uma das coordenadoras, Prof. ${ }^{a}$ Eulália L. Lobo, na Conferência Internacional de História de Empresas, realizada em Outubro de 1991 no Rio de Janeiro, idealizada e organizada pela Prof." Maria Bárbara Levy. Sobre Alfred Chandler ver: "The emergence of managerial capitalism". Business History Review, 58, winter, 1984, pp. 478 - 503; Thomas K. McCrawm (ed.), The essencial Alfred Chandler. Essays toward a historical theory of big business. Boston, Massachusetts, Harvard Business Scholl Press, 1988.

${ }^{4}$ Sobre a questão da identidade cultural da empresa e da necessidade de uma história ver: a revista Entreprises et Histoire, Paris, Editions ESKA, abril, 1992, n. ${ }^{\circ} 1$, pp. 91-112; José Amado Mendes, "Cultura de empresa: uma nova dinâmica organizacional", Gestão e Desenvolvimento, Viseu, Universidade Católica Portuguesa, n. 1 1, 1992, pp. 49-57.

${ }^{5}$ Sobre este ponto ver: "Scale and Scope: a Review Colloquium", Business History Review, vol. 64, n. 4 , winter, 1990, pp. 690-758, especialmente as contribuições de Thomas Hughes e Albert Fishlow. 


\section{BIBLIOGRAFIA}

BARROS, Geraldo Mendes (1982), Guilherme Guinle. 1882-1960, Rio de Janeiro, Livraria Agir Editora.

BESOUCHET, Lídia (1978), Mauá e seu tempo, Rio de Janeiro, Nova Fronteira.

BOUVIER, J. (1976). "O Aparelho conceptual na história económica", Maria Beatriz Nizza da Silva (org.), Teoria da História, São Paulo, Cultrix, p. 135 e segs.

CARDOSO, Ciro F. (1988), Ensaios racionalistas, Rio de Janeiro, Campus.

CASTRO, Ana Célia (1988), Crescimento da firma e diversificação produtiva. $O$ caso Agroceres, Unicamp, Instituto de Economia, Campinas.

CIPOLLA, Carlo, M. (1991), Between history and economics. An introduction to Economic History, Oxford, Brasil Blackwell.

DAVIET, Jean-Pierre (1990), “Aniches et nouveaux visages de la Business History", L'usine et le bureau, Lyon, Press Universitaire de Lyon.

FAUSTO, Boris (Org.) (1985), O Brasil Republicano. Estruturas de poder e economia (18891930), São Paulo, Difel, Tomo III, vol. I.

FREITAS FILHO, Almir P. (1989), "História económica e História de empresas: algumas reflexões metodológicas”, Ensaios FEE. 10(1): 168-177, Porto Alegre, FEE Siegfried Emanuel Heuser.

GIROLETTI, Domingos (1991), Fábrica Convento Disciplina, Belo Horizonte, Imprensa Oficial.

GRAHAM, Richard (1966), "A British industry in BraziL: Rio Flour Mill, 1886-1920", Business History, vol. VIII, n.' 1, p. 13-38.

HANNAH, Leslie (1983), "New issues in British Business History”, Business History Review, vol. LVII, n. ${ }^{\circ}$, Summer, p. 166-167.

LIBBY, Douglas C. (1984), Trabalho escravo e capital estrangeiro no Brasil. O caso de Morro Velho, Belo Horizonte, Itatiaia.

MARTINS, José de Souza (1976), Conde Matarazzo, o empresário e a empresa, 2". ed., São Paulo, Hucitec.

OLSSON, Ulf (1990), "Business History and Economic History”, Scandinavian Economic History Review, vol. XXXVIII, $\mathrm{n}^{\circ} 2$.

TEIXEIRA, Palmira P. (1990), A Fábrica e o sonho: trajectória do industrial Jorge Street, Rio de Janeiro, Paz e Terra.

VAZ, Allison Mascarenhas (1990), C.i Cedro e Cachoeira. História de uma empresa familiar (1883-1987), Belo Horizonte, C. ${ }^{\text {ia }}$ De Fiação e Tecidos Cedro e Cachoeira S. A.

WEID, Elizabeth von der; BASTOS, Ana Marta R. (1986), O Fio da meada. Estratégia e expansão de uma indústria têxtil: Companhia América Fabril: 1878-1930, Rio de Janeiro, Fundação Casa de Rui Barbosa, Confederação Nacional da Indústria. 